\title{
Customized Standalone GIS-Based Tool for Ground Water Quality Assessment: Gaza Strip as a Case Study
}

\author{
Fahid K. J. Rabah', Al-Moataz Billah E. Budwan², Said M. Ghabayen ${ }^{1}$ \\ ${ }^{1}$ Civil and Environmental Engineering Department, Faculty of Engineering, IUG, Gaza, Palestine; ${ }^{2}$ United Nations Relief and Works \\ Agency, Gaza Field Office, Gaza, Palestine. \\ Email: frabah@iugaza.edu,m.budwan@yahoo.com,Sghabayen@iugaza.edu
}

Received February $26^{\text {th }}, 2013$; revised March 27 ${ }^{\text {th }}, 2013$; accepted April $6^{\text {th }}, 2013$

Copyright (C) 2013 Fahid K. J. Rabah et al. This is an open access article distributed under the Creative Commons Attribution License, which permits unrestricted use, distribution, and reproduction in any medium, provided the original work is properly cited.

\begin{abstract}
Employing the full versions of GIS software with its numerous functions to manage case-specific applications is becoming inconvenient for many reasons. A convenient solution that is spreading worldwide to solve this problem is to develop customized tools that use the same GIS concept to meet specific applications. The water resource department in Gaza strip has been facing technical and financial difficulties in using the full GIS versions in managing groundwater resources. Thus, the objective of this paper was to develop a customized standalone GIS-Based ground water quality assessment tool (GWQAT) to be used by the water resources management department in Gaza strip. GWQAT was developed using Microsoft visual basic programming language, a regression mathematical model, map objects, and map files generated from ESRI ARC Info. GWQAT was designed to achieve many functions such as mapping, map overlaying, buffering, charting, soil hydro-geological profiling, and predicting future groundwater quality parameters variations. The simplicity and validity of GWQAT was demonstrated by its application on the groundwater quality parameters in Gaza strip wells with emphasis on chloride concentration.
\end{abstract}

Keywords: Geographic Information System; Quality Indicators; Water Resources Managers; Decision-Makers; Standalone Version; Gaza Strip

\section{Introduction}

Water sector planners in Gaza Strip (GS) recognized in an early stage the value of geographic analysis and spatial visualization in the water resource management. Based on that, the Palestinian water authority (PWA) in GS started to use the GIS software in groundwater management since 1997 by establishing a GIS department [1]. This department is responsible for producing groundwater quality mapping for the purpose of managing and monitoring the coastal aquifer [2]. Until recently, only GIS professionals are able to use and manipulate the comprehensive tools available in the GIS system. Current practice of GIS applications in GS indicates the need of decision makers (scientist and engineers) who are not GIS professionals to have access to the GIS data base for better understanding and enhanced decisions. This can be achieved by the development of a customized GIS-based tool for the purpose of groundwater quality assessment that is domain-specific and easy-to-use by incorporating the power of a comprehensive GIS environment into a user-friendly experience [3].

Development of customized GIS applications is becoming a worldwide common practice in many fields. Abdul Jabbar [4] described the GIS functionalities being used to assist in the analysis, selection, prioritization, and implementation of civil engineering projects. In this regard, many GIS applications have been developed in hydrology, hydraulics, water resources, transportation, surveying, environment and other fields of civil engineering to facilitate engineering analysis, modeling, design, implementation, management, and decision making. Nazereh Nejatbakhsh [5] developed a customized GISbased tool for tunnel construction sites management.

Selcuk et al. [6] developed a GIS-based software for the spatial assessment of lifeline reliability map under seismic hazard which was developed by using GeoTools environment. Tait et al. [7] developed a GIS-based risk analysis tool for optimizing the use of groundwater. The tool predicts groundwater quality at potential new urban boreholes and determines the best sites for future water resource development. Marchant et al. [8] developed a 
GIS based tool to assess the potential for water resource contamination due to new development in the Olympic bark in London.

Environmental Systems Research Institute (ESRI), a leading player in the applications indicated that the ideal solution to a prolonged GIS development effort is the availability of a component-based development framework that allows solution providers or an organization's internal developers to rapidly build industry-specific GIS applications [9]. For this reason, ESRI has developed the ArcGIS Engine that consists of a software development kit and a re-distributable runtime required to run applications built on ArcGIS Engine. The ArcGIS Engine Developer Kit includes several developer controls to help creating standalone mapping and GIS applications.

To develop a standalone customized GIS application, developers need to use the ArcGIS engine produced by ESRI. However, the complexity of using this engine by non-GIS professionals in addition to the licensing cost, presents a real barrier to users especially in the developing countries such as Gaza strip. This called for seeking an alternative component that is simpler in use, and freely distributed. The MapWinGIS component was developed in 2005 by Idaho State University (Geospatial Software Lab) to meet these needs as an alternative to existing proprietary GIS components such as ArcEngine form ESRI [10].

The main objective of this study was to develop a standalone GIS-based Groundwater Quality Assessment Tool (GWQAT) that enables the identification of groundwater parameters (e.g. chloride concentration) and drawing their current patterns and future expectations using a regression model within a mapping supported environment. The design concept of the GWQAT incorporated the integration of a database engine with a mapping object tool and a mathematical model to generate a tool assisting water resources engineers identifying behaviors of water wells and estimating their potential characteristics over the coming years. This will enhance the planning and decision making processes in the course of groundwater management in Gaza strip.

\section{Materials and Methods}

\subsection{Materials}

\subsubsection{Study Area}

Gaza Strip is a semi-arid area located between longitudes $34^{\circ} 2^{\prime \prime}$ and $34^{\circ} 25^{\prime \prime}$ east and latitudes $31^{\circ} 16^{\prime \prime}$ and $31^{\circ} 45^{\prime \prime}$ north. It is bordered by the Mediterranean Sea from the west, Egypt from the south and the occupied Palestinian territories from the east and has an area of about $365 \mathrm{~km}^{2}$ (Figure 1) [11].

\subsubsection{Groundwater Quality Parameters Data}

Data regarding time history of groundwater quality pa-

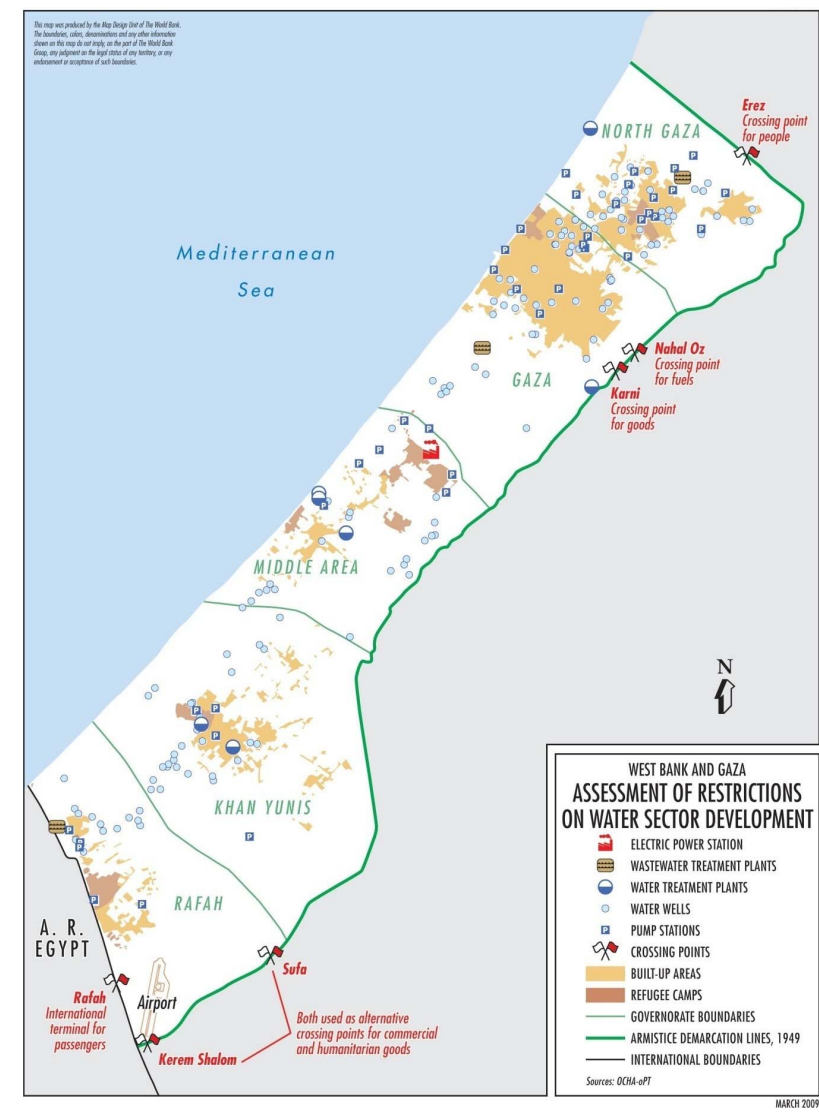

Figure 1. Water wells distribution in Gaza, OCHA [12].

rameters (such as chloride concentration) were collected from the data banks departments of Palestinian Water Authority (PWA), and Coastal Municipalities Water Utility (CMWU). The collected data included detailed records on water quality of 125 well in Gaza area for the years from 1999 through 2005 (625 records). This range of data record (i.e. 1999-2005) was considered in this study for reasons of availability and consistency of data in these years. Figure 1 illustrates the geographical distribution of groundwater wells along Gaza strip. Moreover, shapefiles (thematic maps) of well locations, soil, and land-use along GS were collected from the CMWU GIS department. Figure 2 is an example of the shapefiles that were collected.

\subsubsection{Tools Used for GWQAT Development}

The following tools were used in developing the GWQAT:

\section{1) Microsoft visual basic 6}

The Visual Basic programming language was used as a control container to assemble the multiple controls and components used for the GWQAT development. Microsoft Visual Basic 6 version was used in this study [13].

\section{2) Mapping object}

MapWinGIS.ocx ActiveX control was used as the Mapping object to be integrated into Visual Basic. This 


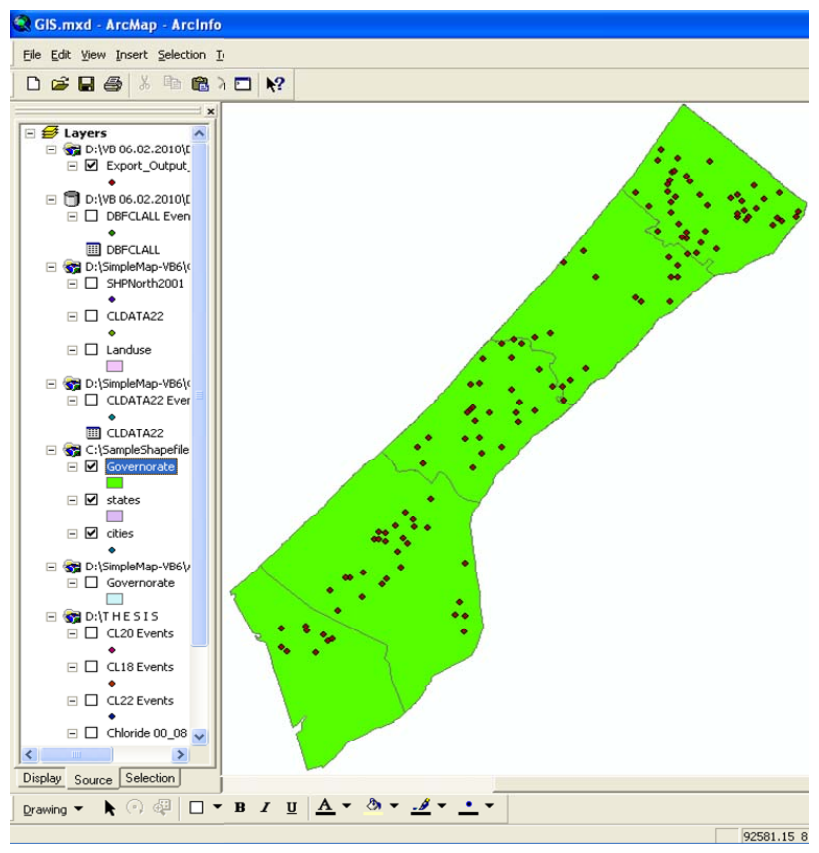

Figure 2. Shapefiles as layers describing wells' location, soil types and land use.

mapping object tool consists of a collection of mapping components and functionalities. It provides the possibility to create customized solutions so as to meet the desktop mapping. This tool enables access to a wide range of data formats ranging from standard GIS formats (ARC Info and ESRI shapefiles) to CAD formats (DXF, DWG, and DGN). This allows performing spatial queries displayed on the map, as well as panning and zooming through multiple map layers [10].

\section{3) Arc info 3.1 (ESRI)}

Arc Info 3.1 GIS software was used for producing the thematic maps and shapefiles needed to build GWQAT [14].

\section{4) Microsoft office suite (excel and access)}

The databases received as excel files were imported to Microsoft Access 97, and segregated according to their locations and IDs.

\subsection{Methodology Used for GWQAT Development}

\subsubsection{Conceptual Design}

The main idea of GWQAT was to produce an easy to use standalone GIS based tool that is capable of introducing the geographical dimension of the tabular data on groundwater quality parameters and to link these data with other spatially distributed datasets such as land use and soil properties data. Another design requirement was that GWQAT should be able to predict future developments in groundwater quality under specified constraints.

GWQAT was built from three main building blocks: a programming language (works as development platform and control container), a mapping object library, and a regression model for the prediction of groundwater quality parameters. In this application, Microsoft Visual Basic 6 (MVB6) was used as the programming Language, MapWinGIS.ocx as the mapping object library, and a mathematical regression model. The standalone MVB6 is not equipped to read mapping files such as shapefiles (e.g. geographical maps), so it was necessary to integrate MapWinGIS.ocx into MVB6 to be able to read such files. The regression model was also integrated in MVB6 to generate the prediction aspect of the tool.

To complete the development of GWQAT, a set of queries and functionalities were programmed utilizing the structured Query Language (SQL) available in MVB6. The main queries that were programmed are: buffering and zoning, threshold, time series charting, land use distribution, and soil type.

\subsubsection{Steps Followed for GWQAT Build Up}

GWQAT was developed through two stages, data Preparation stage and tool building Stage described in steps outlined in Figure 3.

1) Stage one: Data preparation

In this stage tabular data (e g. ground water parameters) was checked, screened, and organized in its form as spreadsheets, which was then converted to GWQAT database file (dbf) to be read from within the Microsoft Visual Basic environment. Moreover, maps (e.g. land use, soil profiles) were processed using Arc Info to produce modified versions of those maps to match with the tabular data.

\section{2) Stage two: Tool building}

In this stage Microsoft Visual Basic 6, has been used as the control container and programming language to assemble and link the main building blocks of the tool together. MapwinGIS.ocx was integrated in VB6 to read and link tabular data with thematic maps.

Other components; namely, polynomial regression model, charting tools, and graphical tools were also integrated in VB6 to be used for manipulation with the tabular data in relation with the thematic maps. Figure 3 summarizes the methodology and logic behind the development of GWQAT.

\section{Results: Presentation of the Developed GWQAT}

GWQAT consists of a user-friendly interface, based on the concept of "What-You-See-Is-What-You-Get", where the user easily moves across multiple functions with the help of clickable icons, combo boxes, and pull-down menus.

The functions within GWQAT can be achieved through two main screens; entry screen and prediction screen. 


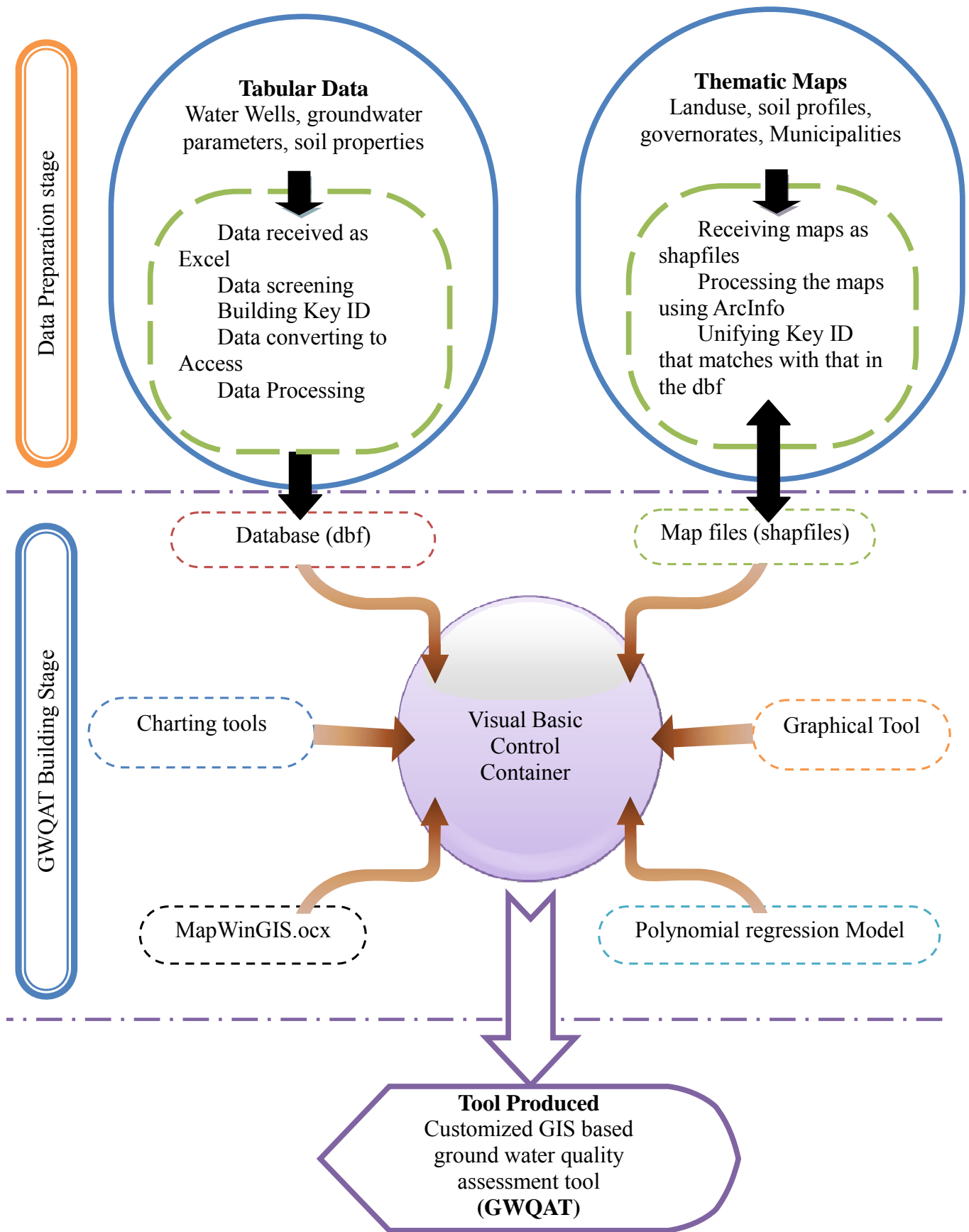

Figure 3. Flow chart of the methodology followed in the development of GWQAT.

The entry screen contains six main functions: Mapping, Threshold, Buffering, Map overlaying, Charting, and soil hydro-geological profiling. On the other hand, the predication screen contains three main functions; polynomial regression, predicated data graphing and predicated data reporting.

The following explanations present the GWQAT functions provided through the above mentioned screens. The chloride concentration $\left(\mathrm{Cl}^{-1}\right)$ as a groundwater quality parameter was used for demonstrating GWQAT func- tions. It should be noted that the GWQAT is equipped to present other groundwater quality parameters as well (e.g. Nitrate, florid, etc.).

\subsection{Entry Screen}

This screen appears immediately after launching the GWQAT (Figure 4), or accessed through clicking button [1. Entry Screen], on this screen, the user will get a default loaded shapefiles of the governorates of Gaza and the geographical distribution of water wells. Concur- 
rently, the GWQAT database file (dbf) is loaded reflecting basic characteristics such as location, time-series of $\mathrm{Cl}^{-1}$ concentration, and soil hydro-geological profile of a default groundwater well selected by GWQAT. The following is a description of the functions available in the entry screen.

\subsubsection{Mapping Function}

Through this function, the user can load shapefiles into the mapping area in the entry screen where he can use the set of maneuvering tool menu (e.g. panning, zooming in/ out, full extent zoom, etc.) to manipulate with the maps presented (Figure 4).

\subsubsection{Charting function}

The user should select a water well from the attributes combo box as it appears in the entry screen (e.g. well No. $\mathrm{D} / 58$ ). A chart showing the time series (over the last five years) of the ground water quality parameter under consideration (e.g. chloride concentration) is then displayed together with well ID, well location ( $\mathrm{x}$ and y coordinates) and average chloride concentration (Figure 5).

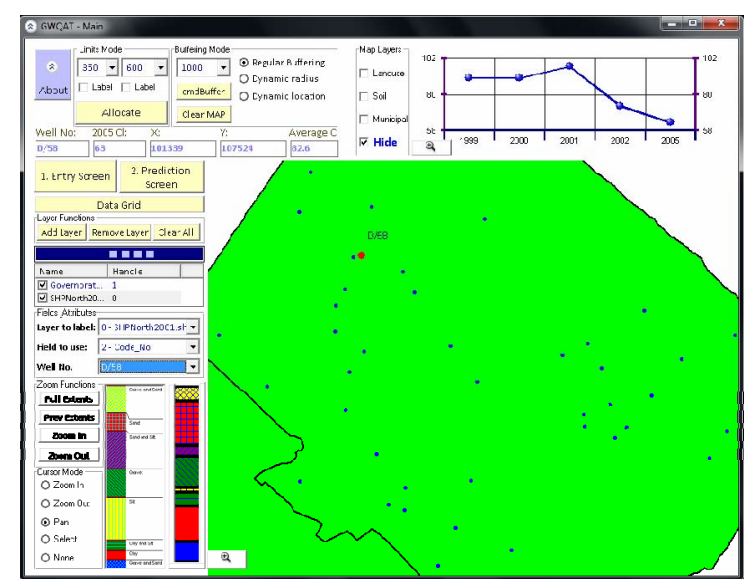

Figure 4. GWQAT main screen outlying the different functions and features.

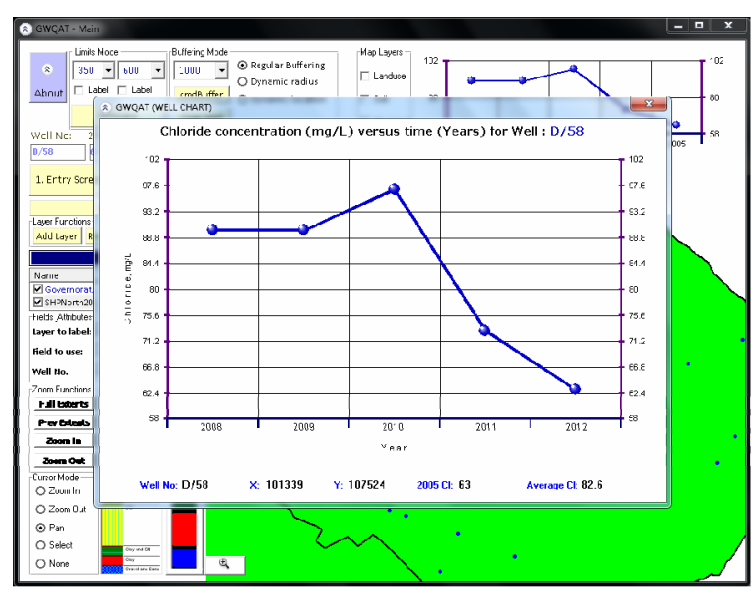

Figure 5. GWQAT charting function screen snapshot.

\subsubsection{Threshold Function}

This function allows the user to set a specific threshold of the chloride concentration in threshold combo box allocating water wells with chloride concentration exceeding a specified concentration (e.g. $350 \mathrm{mg} / \mathrm{l}$ ), in this example 8 wells were identified to exceed that threshold as shown in Figure 6.

\subsubsection{Buffering Function}

This function allows the user to allocate buffer zone of specified radius around a groundwater well to identify wells within that vicinity (e.g. buffer of radius $1200 \mathrm{~m}$ around groundwater well $\mathrm{C} / 113$ provides six wells within the allocated vicinity). The code numbers of these wells are presented in Table $\mathbf{1}$ and appear in the GWQAT screen inside a circle as shown on Figure 7.

Reporting tool presented in exporting tabulated data to MS Excel for further uses provided through a one click button at different screens and functions in the GWQAT. In this example, data for the buffer zone output of e.g. groundwater well $\mathrm{C} / 113$ in above tabulated data is exported to MS Excel (Figure 8).

\subsubsection{Mapping Overlaying}

This function allows maneuvering over multiple layers by displaying relativeness to other mapping layers.

Example groundwater well $\mathrm{C} / 91$ location in respect to other layers such as land-use and soil-type mapping layers Figures 9 and 10 respectively).

\subsubsection{Hydro-Geological Function}

This function allows graphically displaying the hydrogeological profile of a groundwater well in terms of soil strata, and water level (proportional scale), Figure 11.

\subsection{Predication Screen}

This screen is accessed through button labeled [2.

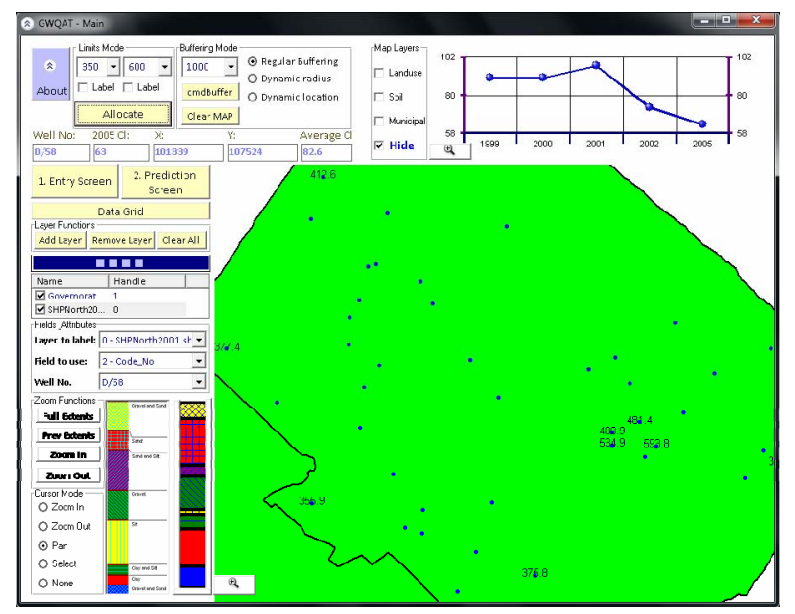

Figure 6. GWQAT threshold function screen snapshot, (applied for $\mathrm{cl}=350 \mathrm{mg} / \mathrm{l})$. 
Table 1. Code No. of the six wells identified by GWQAT in the buffer radius of $1200 \mathrm{~m}$ around well $\mathrm{C} / 113$.

\begin{tabular}{cc}
\hline Well Serial No. & Well Code No. \\
\hline 1 & $\mathrm{~A} / 17$ \\
2 & $\mathrm{C} / 104$ \\
3 & $\mathrm{C} / 49$ \\
4 & $\mathrm{C} / 91$ \\
5 & $\mathrm{C} / 79$ \\
6 & $\mathrm{C} / 78$ \\
\hline
\end{tabular}

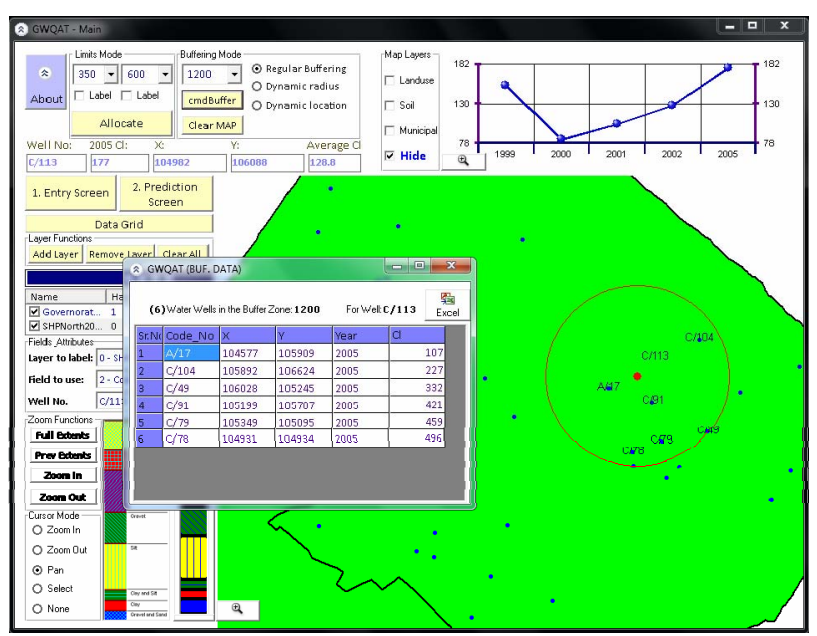

Figure 7. GWQAT buffering function screen snapshot (applied for radius $=1200 \mathrm{~m}$ ).

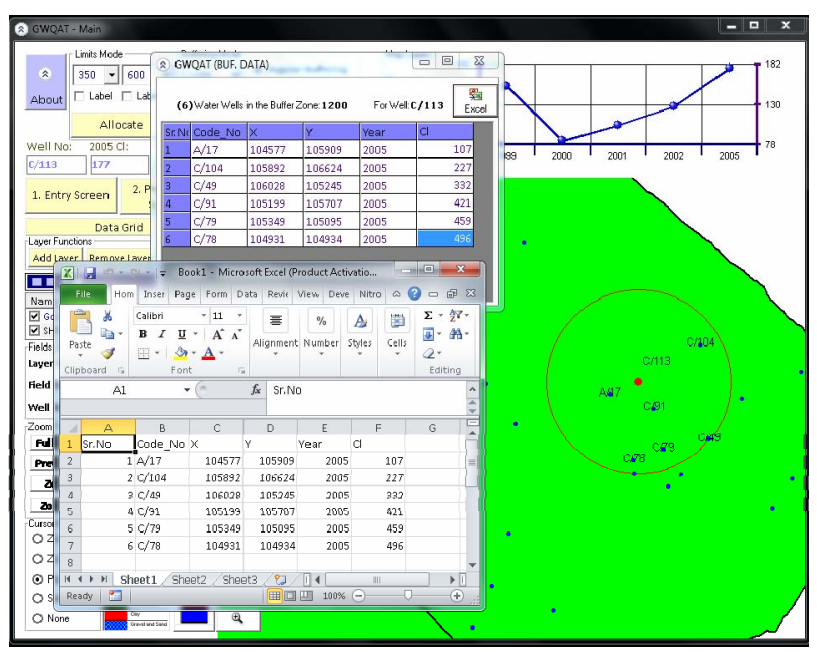

Figure 8. GWQAT reporting facility (exporting to MS excel), screen snapshot.

Predication Screen] from the entry screen, in this screen the user is displaying a set of groundwater wells provided with reasonable number of $\left(\mathrm{Cl}^{-1}\right)$ readings that is used for the GWQAT prediction model, (Figure 12).

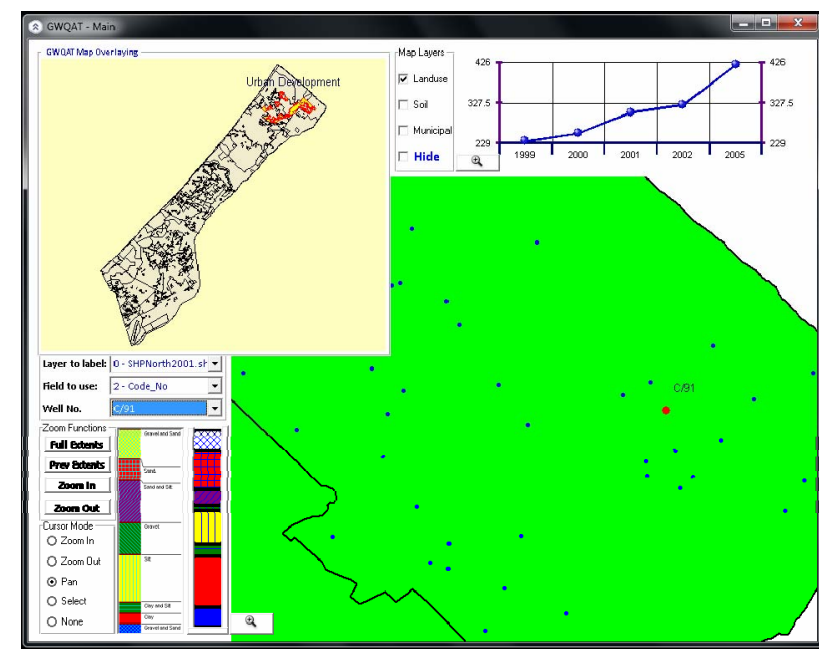

Figure 9. GWQAT map overlaying function screen snapshot (activating land-use map layer).

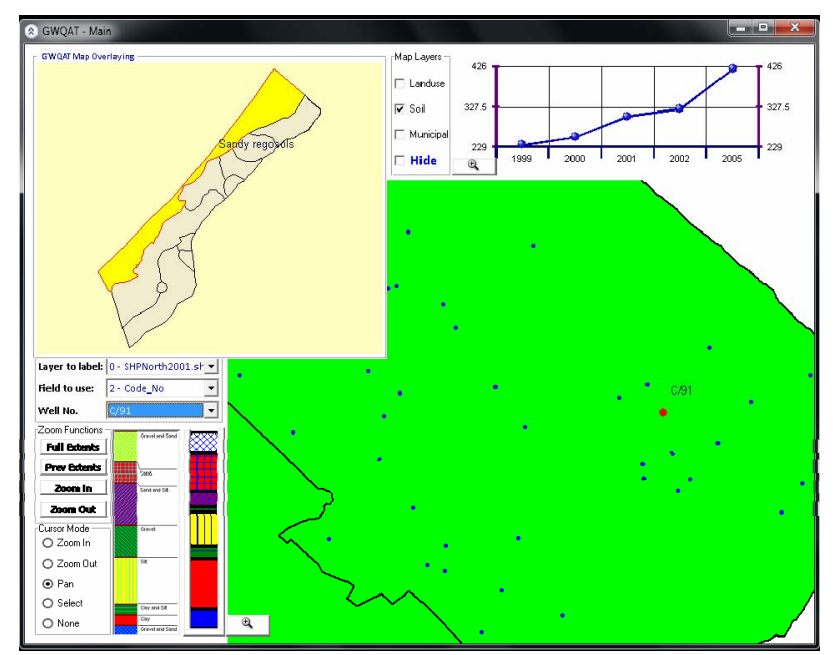

Figure 10. GWQAT map overlaying function screen snapshot (activating soil-type map layer).

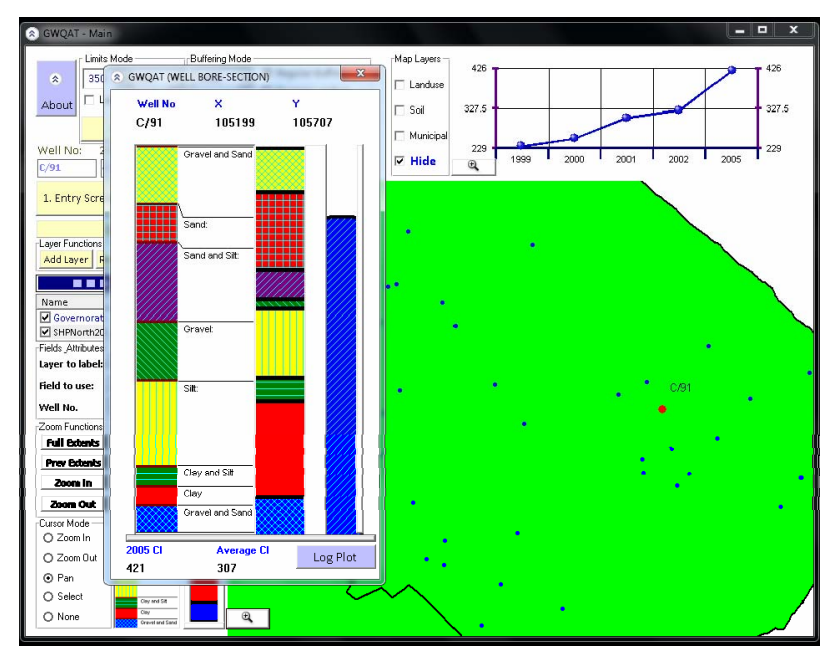

Figure 11. GWQAT hydro-geological Function screen snapshot (soil profile). 


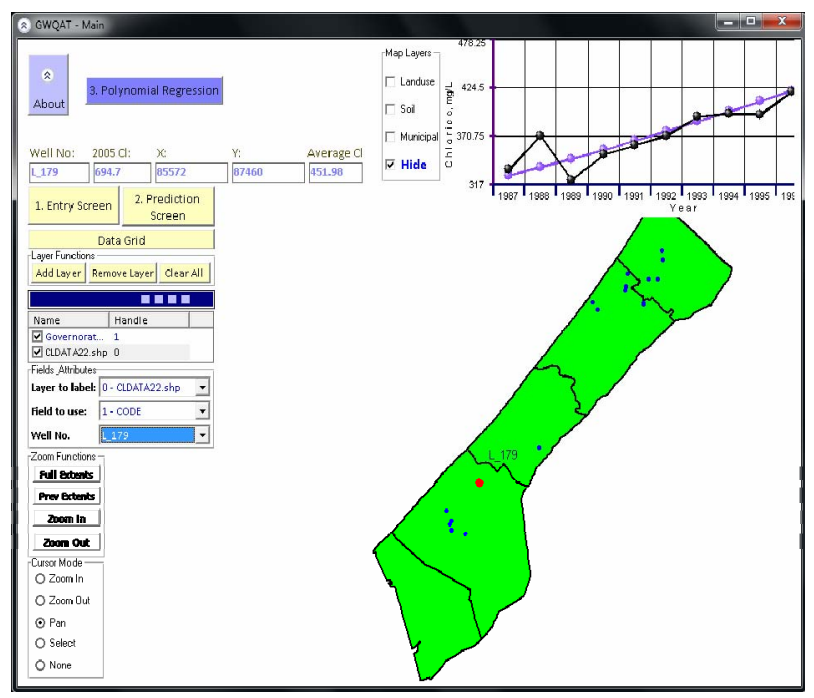

Figure 12. GWQAT predication function screen snapshot (selection of water well).

Selecting groundwater well e.g. R_25D allows the user to access the next screen through clicking on [3. Polynomial Regression] which direct him the polynomial regression output screen, (Figure 13).

In this screen, the results of polynomial regression equation for smaller SSE (Sum of squares of residues) to trend line the actual behavior of the groundwater well (1987-2008) is displayed with equation degree and coefficients respectively as given in Equations (1) and (2) for groundwater well R_25D that has a polynomial regression equation of $3 \mathrm{rd}$ degree:

$$
\begin{aligned}
& Y=(a)+(b) X+(c) X^{2}+(d) X^{3} \\
Y= & (192060166.6719)-(287594.0125) X \\
& +(143.5418) X^{2}-(0.0239) X^{3}
\end{aligned}
$$

Above equation can be used to graphically project $\left(\mathrm{Cl}^{-1}\right)$ concentrations for years to come allowing user to easily interpret the groundwater well quality behavior, in this example graphical illustration of $\left(\mathrm{Cl}^{-1}\right)$ concentrations for years to come until 2020 was displayed, informing the user that $\left(\mathrm{Cl}^{-1}\right)$ for groundwater well R_25D will reach $859 \mathrm{mg} / \mathrm{l}$ in 2015, (Figure 14).

Data generated will be still accessed through other means such as MS Excel, as it is easily exported from with GWQAT, (Figure 15).

\section{Conclusions and Further Developments}

In this paper, a customized standalone GIS-based groundwater quality assessment tool (GWQAT) was developed and presented through the application on groundwater wells in Gaza strip. It was demonstrated that GWQAT is an easy to use tool that is capable of visually introducing the geographical dimension of the tabulated

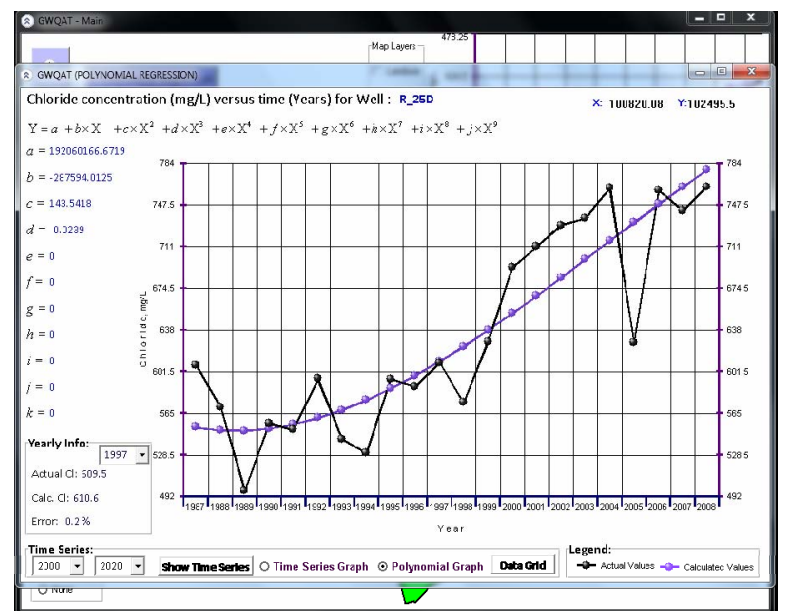

Figure 13. GWQAT polynomial regression output screen (equation generation feature) snapshot.

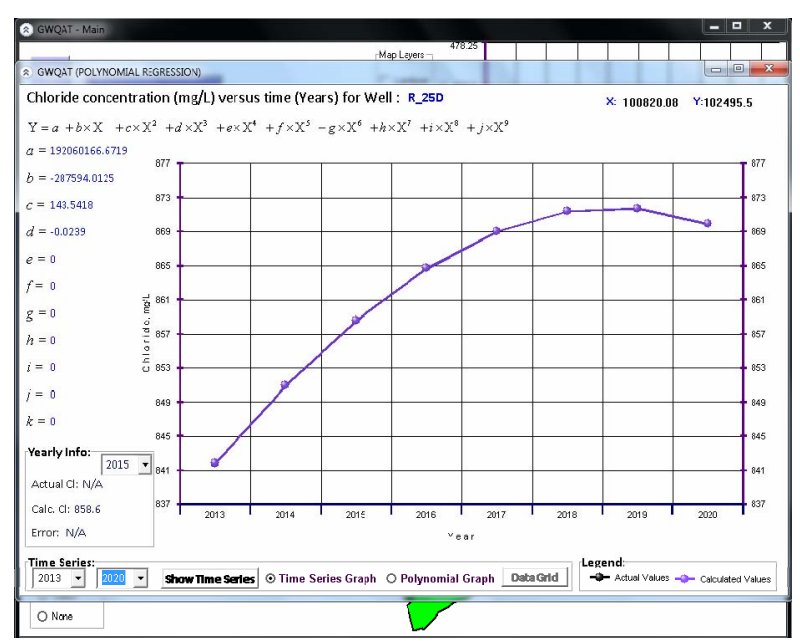

Figure 14. GWQAT polynomial regression output screen (data projection feature) snapshot.

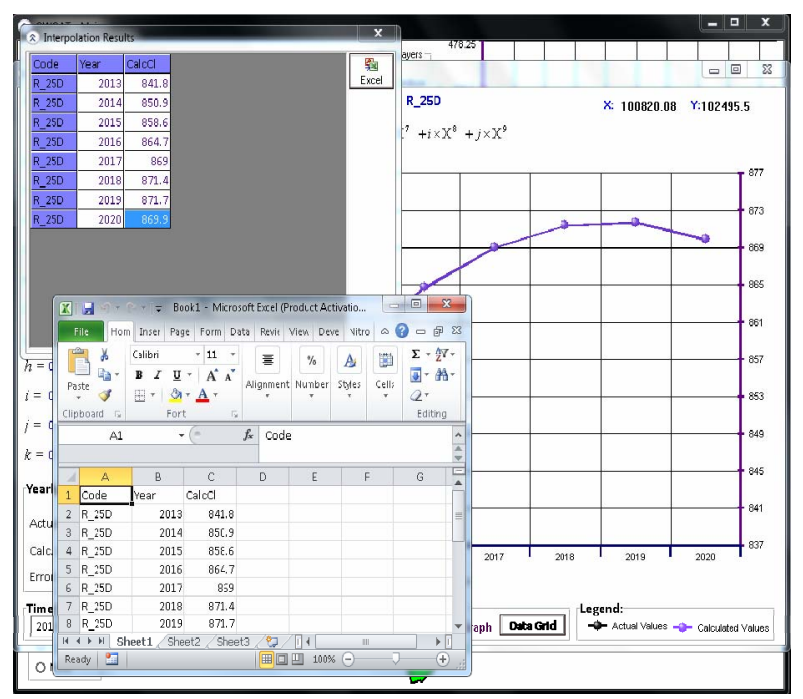

Figure 15. GWQAT polynomial regression output screen (data exporting tool) snapshot. 
data on groundwater quality parameters and to link this data with other spatially distributed datasets such as land use and soil properties. The main functions within GWQAT are: mapping, quality threshold, buffering, map overlaying, charting, and soil hydro-geological profiling. It was also demonstrated that GWQAT is capable to predict future developments in groundwater quality under specified constraints using the GWQAT polynomial regression function and to present the results in tabular forms and high quality charts.

The simplicity of the tool enabled decision makers in the water resource department in PWA who are not GIS professionals to easily run it and produce reports (tables, charts, maps) that supported them in the decision making process regarding ground water assessment and management. Thus, decision makers are no longer required to go through extensive training on full versions of GIS that are known to have numerous functions, not all directly related to the specific applications of groundwater assessment and management. GWQAT has customized many GIS functions that usually take many stages to access through proprietary GIS applications and made them easy-accessed. Moreover, GWQAT saves considerable cost when considering purchasing and licensing off-theshelf GIS applications which present a constraint to GIS users in Gaza.

Developing GWQAT opens the door to develop similar applications in Gaza strip using the same approach for other sectors such as agronomy, industries, and construction management. In addition, GWQAT is subject of further development through introducing more GIS based functions and utilities.

\section{REFERENCES}

[1] F. K. J. Rabah, A. Salha and S. Ghabayen, "Effect of GIS Interpolation Techniques on the Accuracy of the Spatial Presentation of Groundwater Monitoring Data in Gaza Strip," Journal of Environmental Science and Technology, Vol. 4, No. 6, 2011, pp. 579-589.

[2] PWA, "Water Sector Strategic Planning Study, Final Report. Specialist Studies, Part B: Focal Areas," Vol. III, Palestinian Water Authority, 2000.

[3] M. Cheong, R. Appave and S. Jamala, "Developing a Geographic Information System (GIS) Tool for Extension Purposes in Mauritius," Proceedings of the fifth Annual
Meeting of Agricultural Scientists (AMAS), Reduit, 3-4 May 2001, pp. 1-8.

[4] A. Abdul Jabbar, "Using Geographic Information System (GIS) to Manage Civil Engineering Projects," Engineering \& Technology Journal, Vol. 29, No. 7, 2011, pp. 1276-1289.

[5] N. Nejatbakhsh, "Implementation of Customized GISBased Tool for Tunnel Construction Sites Management (Tunnel CS Tool)," The International Archives of the Photogrammetry, Remote Sensing and Spatial Information Sciences, Vol. XXXVII, Part B2, Beijing, 2008, pp. 1015-1022.

[6] A. Selcuk, H. Duzgun and L. Oduncuoglu, "A GIS-Based Software for Lifeline Reliability Analysis under Seismic Hazard," Computers \& Geosciences, Vol. 42, 2012, pp. 37-46. doi:10.1016/j.cageo.2012.01.015

[7] N. Tait, R. Davison, J. Whittaker, S. Leharne and D. Lerner, "Borehole Optimization System (BOS)—A GIS Based Risk Analysis Tool for Optimizing the Use of Urban Groundwater," Environmental Modeling and Software, Vol. 19, No. 12, 2004, pp. 1111-1124. doi:10.1016/j.envsoft.2003.11.014

[8] A. P. Marchant, V. J. Banks, K. R. Royse and S. P. Quigley, "The Developed of a GIS Methodology to Assess the Potential for Water Resource Contamination due to New Development in the 2012 Olympic Park Site, London," Computers and Geosciences, Vol. 51, 2013, pp. 206-215. doi:10.1016/j.cageo.2012.09.006

[9] Environmental Systems Research Institute, "Delivering Custom GIS Applications with ArcGIS Engine," An ESRI White Paper, 2004.

[10] D. Ames, C. Michaelis and T. Dunsford, "Introducing the MapWindow GIS Project," The Journal of the Open Source Geospatial Foundation, Vol. 2, 2007, pp. 1-5.

[11] MOPIC, "Master Plan for Sewage and Stormwater in the Gaza Governorate," Final Master Plan Report, Palestinian National Authority, Ministry of Planning and International Cooperation, 1998.

[12] United Nations Office for the Coordination of Humanitarian Affairs in the Occupied Palestinian Territory, 2012. www.ocha.org

[13] Microsoft Corporation, "Microsoft Visual Basic 6.0 Programmer's Guide," Microsoft Corporation, Washington, 1996.

[14] Environmental Systems Research Institute, "The Arc/Info Version 3.1 Software Package Documentation," ESRI, Redlands, 1997. 